\title{
Antioxidant and Oxidant Levels of Pepper (Capsicum annuum cv. 'Charlee') Infected with Pepper Mild Mottle Virus
}

\author{
Murat DIKILITAS ${ }^{1 *}$, Mehmet Ertugrul GULDUR ${ }^{1}$, Ahmet DERYAOGLU $^{2}$, Ozcan EREL $^{3}$ \\ ${ }^{1}$ Harran University, Faculty of Agriculture, Department of Plant Protection, Osmanbey Campus, \\ 63200 S.Urfa, Turkey; m.dikilitas@gmail.com (*correspondingauthor) \\ ${ }^{2}$ Food and Agricultural Engineer-Trabzon, Turkey \\ ${ }^{3}$ Ataturk Research and Educational Hospital, Ministry of Health, Ankara, Turkey
}

\begin{abstract}
Total antioxidant status (TAS), total oxidant status (TOS), as well as total phenol (TP), free phenol (FP), conjugated phenol (CP), and the vitamin C content of pepper plants (Capsicum annuum cv. 'Charlee') infected with Pepper mild mottle virus (PMMoV) were determined via a novel automated antioxidant system using test kits. PMMoV was first identified in Turkey in 1994 in commercial pepper (Capsicum annumm cv. 'Charlee') fields and caused an outbreak in southern Turkey by 2006, especially in greenhouses. Infected plants were confirmed by ELISA using commercial kits for the virus. The infected plants had stunted growth; and leaves and fruits became mottled, puckered, malformed, deformed, and marked by off-colored sunken areas. Fruits expressing virus symptoms were utilized for biochemical analyses. The percent ratio of TOS to TAS was calculated as the oxidative stress index (OSI). The TAS level and the vitamin $\mathrm{C}$ content were found to be significantly lower in infected peppers as compared to healthy peppers. However, TOS, OSI, TP, FP, and CP levels were significantly higher in infected pepper fruits than in healthy ones. In this study, it has been demonstrated that low levels of TAS and high levels of TOS, as well as high OSI status, reflects the quality of peppers. Using this method, the quality of fruits and the condition of plants can be determined in advance of stress development.
\end{abstract}

Keywords: antioxidant, phenol, pepper mild mottle virus, PMMoV, total oxidative status, total antioxidant status, vitamin C

Abbreviations: TAS: Total Antioxidative Status; TOS: Total Oxidative Stress; OSI: Oxidative Stress Index; TP: Total Phenol; FP: Free Phenol; CP: Conjugated Phenol; ROS: Reactive Oxygen Species

\section{Introduction}

Sweet and hot peppers are one of the most important vegetable species in Turkey, as well as in other parts of the world. Turkey ranks fourth in the world in regards to vegetable production and second in rank, by 1.84 million tons, in terms of pepper production (Ozalp, 2009). Pepper crops can be grown in fields and in greenhouses, however, their average yields are severely impacted by the presence of pests and diseases. The main restricting factor in the yield of pepper quantity, as well as quality, is infection of virus diseases (Anandakumar et al., 2008). Although several viruses are known to infect peppers, PMMoV has been severely damaging the fruits of peppers, in fields and in greenhouses, in recent years (Aycicek et al., 2006; Güldür and Çağlar, 2006). The geographic distribution of $\mathrm{PMMoV}$ has been reported to include North America, Australia, Japan, Korea, and Europe (Brunt et al., 1996). Infected plants exhibit stunted growth, mottling, puckering, malformed leaves, and the fruits are generally small and deformed and marked by off-colored sunken areas (Güldür and Çağlar, 2006). If plants are infected when they are young symptoms may become more severe. However, symptoms may vary depending on the cultivar. In severe cases, the virus can lead to a $75-95 \%$ loss in yield (Güldür and Çağlar, 2006). Symptoms of virus infection in pepper plants usually develops within 1-3 weeks of infection (Anandakumar et al., 2008). When plants are attacked by pathogens they respond by activating a variety of defense mechanisms, including the rapid production and accumulation of ROS (reacting oxygen species) (Kiraly et al., 2008). On the other hand, the phenolic content of the plants increases as a response of the defense mechanism (Katoh et al., 2009). The status of TAS, TOS, and OSI, as well as the phenolic content of virus-infected peppers, reflects the condition and resistance of pepper plants. In this study, wit has been used a novel automated method developed by Erel (2004a; 2005) for measuring TAS and TOS, and determined the level of OSI based on the ratio between TOS and TAS in order to ascertain the health and the antioxidative status of pepper fruits. Infected and healthy (virus-free) plants were compared in order to evaluate the relationships between oxidative stress and fruit quality. 


\section{Materials and methods}

\section{Plant material and growth condition}

Seedlings of $C$. annuum cv. 'Charlee' with six to seven leaves were purchased from a commercial supplier in the southern part of Turkey. Plants were then grown in a greenhouse where they were maintained in pots $(25 \mathrm{~cm}$ in diameter) that contained horticultural sand and peat (1:1). During the experimental trial the average day/night temperature was determined to be $23-25^{\circ} \mathrm{C} / 15-18^{\circ} \mathrm{C}$ for a photoperiod of $16 \mathrm{~h}$.

\section{Inoculation of plants with PMMoV}

Virus isolates were made from the naturally infected pepper plants grown in greenhouses and propagated in pepper plants. Sap was extracted from the pepper plants by grinding young leaf tissue into a $0.3 \mathrm{M}$ potassium phosphate buffer $(1: 10 ; \mathrm{w} / \mathrm{v}, \mathrm{pH} 7.2)$ using a prechilled mortar and pestle. The homogenate was centrifuged at $10,000 \mathrm{~g}$ for 5 minutes. Thirty plants were then inoculated with the supernatant containing PMMoV by gently rubbing three of the bottom leaves of the plants with diatomaceous earth while wearing supernatant-wetted gloved fingers. Control plants were treated in the same manner using distilled water. After two weeks of inoculation, the infection was confirmed using ELISA.

\section{The ELISA test}

An ELISA test was carried out in order to confirm the existence of PMMoV in inoculated plants. Leaf tissue was ground in phosphate buffered saline with Tween 20 (1/10; $\mathrm{w} / \mathrm{v}$ ) using a pre-chilled mortar and pestle, and the extract was tested using commercial ELISA kits. Absorbance values $\left(\mathrm{A}_{405 \mathrm{~nm}}\right)$ that were nearly two-fold the maximum negative control value (ELISA index $>2$ ) were considered as positive (Clark and Adams, 1997).

\section{Sampling for oxidative stress}

Fruit samples expressing PMMoV symptoms were collected after 60 days of inoculation from infected and control groups. Thirty samples were evaluated for TAS, TOS, OSI, vitamin C, and TP and FP content.

\section{Samplepreparation}

A $1 \mathrm{~g}$ sample of the pepper tissues from fruit samples were cut into small pieces and homogenized with $10 \mathrm{ml}$ of a $50 \%$ aqueous ethanol solution and sonicated. The sonicated homogenate was filtered through four layers of cheesecloth and centrifuged at $10,000 \mathrm{~g}$ for $15 \mathrm{~min}$. The supernatant was re-centrifuged at $10,000 \mathrm{~g}$ for $10 \mathrm{~min}$ and used for the TAS, TOS, and vitamin C assays (Dikilitas et al., 2011; Velioglu et al., 1998).

\section{Measurements of total antioxidant status (TAS)}

TAS levels for the infected and control groups of peppers were determined using a novel automated method developed by Erel (2004a). In this method, the antioxidative effect of the sample as a result of potent-free radicals, which are initiated by the production of hydroxyl radical, is measured spectrophotometrically. Antioxidants present within the sample supress oxidation reactions and color formation. In other words, they accelerate the bleaching rate proportional to their concentrations. The reaction can be monitored spectrophotometrically and the bleaching rate is inversely related to the TAS of the sample. The assay has excellent precision values that are lower than $3 \%$. Suppression of color formation can be calibrated using Trolox, which is widely used as a traditional standard for TAS measurement assays, with assay results expressed in mmol Trolox equiv/g fresh weight (Erel, 2004b). Following a manual spectrophotometric optimization process, the method was applied while using an automated analyzer, Aeroset. The assay was carried out as follows: $200 \mu \mathrm{l}$ of Reagent 1 [(o-dianisidine $(10 \mathrm{mM})$, ferrous ion $(45 \mu \mathrm{M})$ in Clark and Lubs solution (75 mM, pH 1.8)], was mixed with $10 \mu \mathrm{l}$ of Reagent $2\left[\mathrm{H}_{2} \mathrm{O}_{2}(7.5 \mathrm{mM})\right.$ in Clark and Lubs solution], and $5 \mu \mathrm{l}$ of the sample extract was added to the mixture. The mixture was then read at $444 \mathrm{~nm}$ for $3 \mathrm{~min}$.

\section{Measurements of total oxidant status (TOS)}

TOS levels were determined using a novel automated measurement method developed by Erel (2005). In this method, oxidants present in the sample oxidize the ferrous ion-o-dianisidine complex to ferric ion. The oxidation reaction is enhanced by glycerol molecules, which are abundantly present in the reaction medium. In an acidic medium, the ferric ion makes a colored complex with xylenol orange. The color intensity, which can be measured spectrophotometrically, is related to the total amount of oxidant molecules present in the sample. The assay is calibrated with hydrogen peroxide, and the results are expressed as $\mu \mathrm{mol} \mathrm{H}_{2} \mathrm{O}_{2}$ equiv/l. The assay was carried out as follows: $225 \mu \mathrm{l}$ solution of Reagent $1(150 \mu \mathrm{M}$ xylenol orange, $140 \mathrm{mM} \mathrm{NaCl}$, and $1.35 \mathrm{M}$ glycerol in a $25 \mathrm{mM}$ $\mathrm{H}_{2} \mathrm{SO}_{4}$ solution, $\mathrm{pH} 1.75$ ) was mixed with $11 \mu$ l Reagent $2(5 \mathrm{mM}$ ferrous ion and $10 \mathrm{mM} o$-dianisidine in a 25 $\mathrm{mM} \mathrm{H} \mathrm{SO}_{4}$ solution) and $35 \mu \mathrm{l}$ sample extract was added to the mixture. The mixture was then read at 560 and 800 $\mathrm{nm}$ for $3 \mathrm{~min}$.

\section{Measurements of vitamin $C$}

The reduced ascorbate concentration was measured with the FRASC assay using ascorbate oxidase (Benzie and Strain, 1999).

\section{Measurements of the oxidative stress index (OSI)}

The percent ratio of TOS to TAS level has been accepted as the oxidative stress index (OSI) (Benzie and Strain, 1999; Dikilitas et al., 2011; Erel, 2004a; Kosecik et al., 2005). In order to perform the calculation, the unit of TAS, mmol Trolox equivalent/g, was changed to $\mu \mathrm{mol}$ 
60

Trolox equivalent/g, and the OSI value was calculated according to the following formula:

OSI $=\left[\left(\right.\right.$ TOS, $\mu \mathrm{mol} \mathrm{H}_{2} \mathrm{O}_{2}$ equivalent $\left./ \mathrm{g}\right) /(\mathrm{TAS}, \mu \mathrm{mol}$ Trolox equivalent $/ \mathrm{g}) \times 100]$.

\section{Measurements of the total and free phenolic content}

Total phenols (TP), conjugated phenols (CP), and free phenols (FP) of fruits were determined by the Folin-Ciocalteu assay which involves a reduction of the reagent by phenolic compounds, with the concomitant formation of a blue complex. Intensity at $760 \mathrm{~nm}$ increases linearly with the concentration of phenols in the reaction medium (Singleton et al., 1999). In this study, catechin was preferred to gallic acid since the activity of the catechin substrate gave better results (Dikilitas et al., 2011). The phenolic content of fruits were determined from the calibration equations and were expressed as catechin equivalents $\mathrm{g}^{-1}$ Fwt (Imeh and Khokhar, 2002).

\section{Chemicals}

Vitamin C (L (+) ascorbic acid); ascorbate oxidase; gallic acid; 2,2-azino-bis (3-ethylbenz-thiazoline-6-sulfonic acid) (ABTS); 2,4,6-tripyridyl-striazine (TPTZ); xylenol orange (o-cresosulfonphthalein-3,3-bis (sodium methyliminodiacetate)); sulfuric acid; acetic acid; sodium acetate; hydrochloric acid; orthodianisidine dihydrochloride; glycerol; ethanol; ferrous ammonium sulfate; catechin; hydrogen peroxide; and Folin-Ciocalteu's phenol reagent were purchased from Sigma (Missouri, USA) and Merck Co (New Jersey, USA). The water-soluble analogue of vitamin E (Trolox; 6-hydroxy-2,5,7,8-tetramethylchroman-2-carboxylic acid) was purchased from the Sigma-Aldrich Chemical Co. (Missouri, USA). All chemicals were the ultra pure grade, and type I reagent-grade deionized water was utilized.

\section{Statistical analyses}

Values were expressed as the mean \pm SE. The means of the groups were compared using a one way analysis of variance (ANOVA). A p value less than 0.05 was accepted as significant. Data were analyzed using SPSS (Illinois, USA) for the Windows (Microsoft, USA) computing program (Version 11.0).

\section{Results and discussion}

The oxidative, antioxidative, and phenolic content of the peppers infected with $\mathrm{PMMoV}$, as well as the control plants, are presented in Tab. 1. The TAS and vitamin C contents of the control plants were higher than those of the PMMoV infected pepper plants while the TOS, OSI, and phenolic contents, including FP and CP, were found to be lower than the infected pepper plants. For example, the TAS and Vitamin C levels of the control plants were 2.75 and 1.97 times higher, respectively, than those of infected plants. On the other hand, biochemical responses such as TOS, OSI, and phenol levels generated under biotic stress conditions were $1.35,3.72$, and 1.20 times higher, respectively, than that generated under stress-free conditions. Significant negative correlations also existed between vitamin $\mathrm{C}$ and OSI in both the control $(\mathrm{r}=-0.41$, $p<0.05)$ and infected plants $(r=-0.77, p<0.05)$. Infected plants displayed a lower content of vitamin $C$ when the OSI level of infected plants increased (Fig. 1).

Fruits and vegetables contain significant levels of biologically active components that provide a major source of dietary antioxidants that increase plasma antioxidant capacity (Krishna et al., 2010). Thus, the consumption of fruits and vegetables has been associated with a lower incidence of and lower mortality rates caused by cancer in several human cohorts, as well as case-control studies for all common types of cancer. For example, Anandakumar et al. (2008) stated that the effect of a pungent ingredient of red pepper, capsaicin, restored cellular metabolism by mitigating the oxidative stress that induced changes in the antioxidant defense system by benzo(a)pyrene in the lungs of mice. Pepper and its products are rich in health related food components and are a good source of vitamin C. Numerous reports have been published on the antioxidant activity of vegetables and crop plants (Perucka, et al., 2010). For example, potatoes, broccoli (Al-Saikhon et al., 1995; Cao et al., 1996), mushrooms, white cabbage, and cauliflower (Gazzani et al., 1998), and kidney and pinto beans (Pengelly et al., 2010) have been reported to have high antioxidant activities.

Reports regarding the antioxidant capacity of peppers have recently been updated and have gained significant attention (Anandakumar et al., 2008; Dikilitas et al., 2011; Keçeli, 2008; Perucka et al., 2010). Peppers are an important crop due to the economic and nutritional value of fruits, and since they are an excellent source of antioxidant compounds such as vitamin $\mathrm{C}$ and carotenoids (Navarro $e t$ al., 2006). However, abiotic and biotic stress factors reduce fruit yields and crop production, as well as quality. The deterioration of fruit quality has commonly been reported to result from abiotic stress factors in pepper plants as a result of biochemical responses. Very few reports describing PM$\mathrm{MoV}$ virus infections of pepper plants have been reported. In general, abiotic and biotic stresses generate ROS such as $\mathrm{O}_{2}$ and $\mathrm{H}_{2} \mathrm{O}_{2}$ in plant cells, and their overproduction is a common consequence of stress factors. However, plants respond to stress by ameliorating the danger that results from the presence of cellular oxidants. Under these conditions, there should be a balance between the generation and the degradation of ROS, otherwise oxidative injuries are inevitable. Therefore, plants, in general, have evolved complex defense mechanisms for detoxifying $\mathrm{O}_{2}^{-}$and $\mathrm{H}_{2} \mathrm{O}_{2}$ (Dikilitas et al., 2009; Diwan et al., 2010). The primary components of antioxidant systems consist of antioxidant enzymes (superoxide dismutase, catalase, peroxidase, and glutathione reductase) and non-enzymatic low molecular weight antioxidants (glutathione, proline, caro- 
Tab. 1. Comparison between the oxidative-antioxidative parameters and the phenolic content of peppers

\begin{tabular}{ccc}
\hline Parameters & Control Peppers, $\mathrm{n}=30$ & Infected Peppers, $\mathrm{n}=30$ \\
\hline TAS, $\mu$ mol Trolox Eq g ${ }^{-1}$ Fwt & $8.8^{\mathrm{a}} \pm 1.2$ & $3.2^{\mathrm{b}} \pm 0.28$ \\
TOS, $\mu$ mol $\mathrm{H}_{2} \mathrm{O}_{2} \mathrm{Eq} \mathrm{g}^{-1}$ Fwt & $0.174^{\mathrm{a}} \pm 0.015$ & $0.235^{\mathrm{b}} \pm 0.012$ \\
OSI, Arbitrary Unit & $1.97^{\mathrm{a}} \pm 0.03$ & $7.34^{\mathrm{b}} \pm 0.02$ \\
Vitamin C, $\mu$ mol g $^{-1}$ Fwt & $4.12^{\mathrm{a}} \pm 0.06$ & $2.09^{\mathrm{b}} \pm 0.05$ \\
Total phenol, $\mu$ mol catechin Eq g ${ }^{-1}$ Fwt & $0.213^{\mathrm{a}} \pm 0.02$ & $0.256^{\mathrm{b}} \pm 0.03$ \\
Free phenol, $\mu$ mol catechin Eq g ${ }^{-1}$ Fwt & $0.152^{\mathrm{a}} \pm 0.01$ & $0.175^{\mathrm{b}} \pm 0.03$ \\
Conjugated phenol, $\mu$ mol catechin Eq g ${ }^{-1}$ Fwt & $0.087^{\mathrm{a}} \pm 0.01$ & $0.121^{\mathrm{b}} \pm 0.02$ \\
\hline
\end{tabular}

TAS: Total Antioxidant Status; TOS: Total Oxidant Status; OSI: Oxidative Stress Index; p: Significance was defined as $p<0.05$. Letters different from each other above the numbers in the same lines are statistically significant. Values were expressed as mean $\pm S E(p<0.05)$
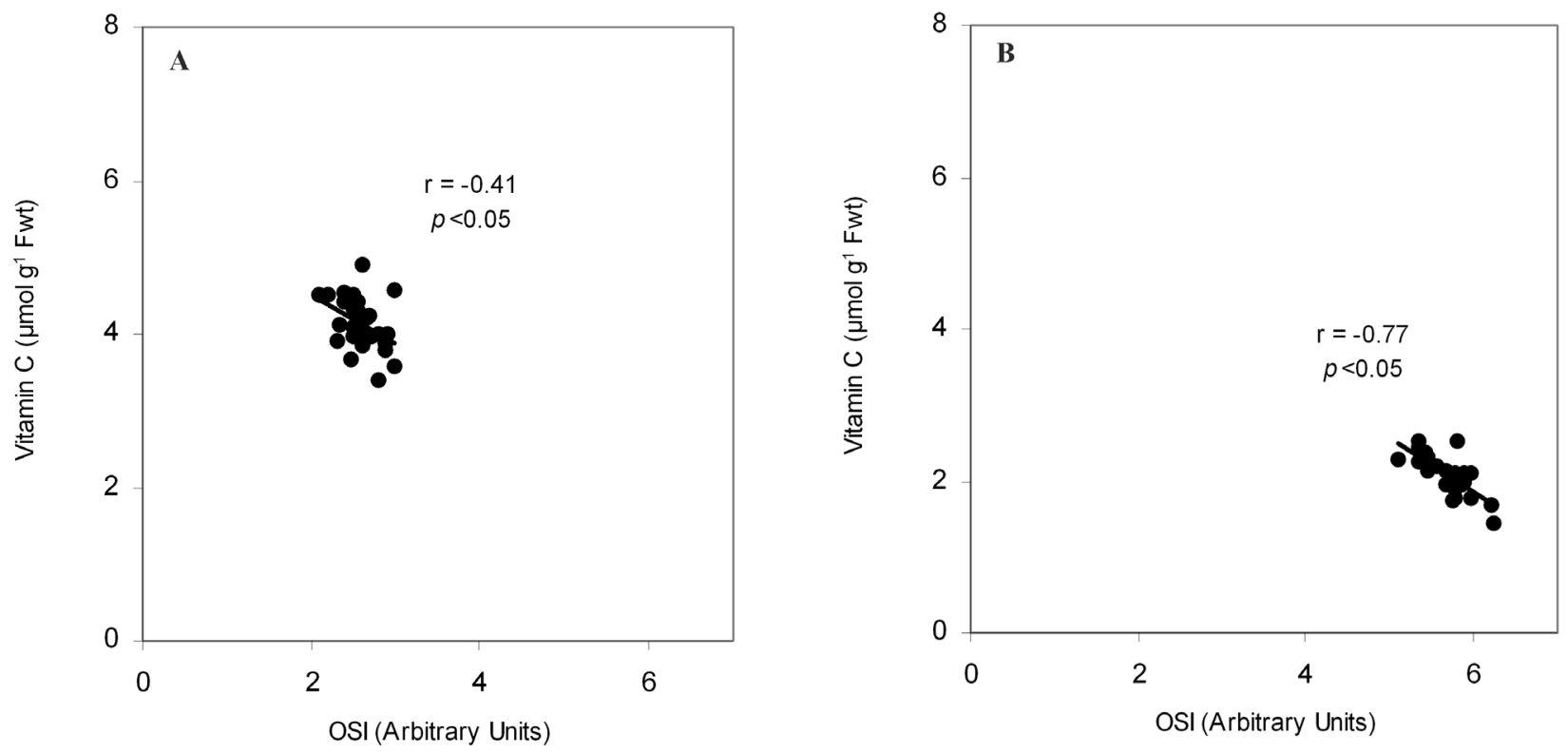

Fig. 1. The correlation between the content of OSI and vitamin C in C. annuum cv. 'Charlee' pepper plants-(A) the control group, and (B) the pepper mild mottled virus-infected group

tenoids, ascorbate, and tocopherols) (Panda and Khan, 2009). Many studies regarding the relationship of virus infection on plant antioxidant status have revealed that the antioxidant capacity was significantly reduced. For example, catalase activity has been shown to decline following TMV infection (Brunt et al., 1996). Similarly, changes in ascorbate and glutathione levels and changes in the activities of ascorbate peroxidase, catalase, dehydroascorbate reductase (DHAR), glutathione reductase (GR), glutathione S-transferase (CST), and superoxide dismutase (SOD) declined following a TMV inoculation of tobacco plants (Fodor et al., 1997). On the other hand, stress metabolites such as $\mathrm{H}_{2} \mathrm{O}_{2}$ and MDA (malondialdhyde) tend to increase following virus infections. For example, higher $\mathrm{H}_{2} \mathrm{O}_{2}$ and MDA concentrations were recorded in bean yellow mosaic virus (BYMV) virus-infected faba bean leaves as compared to corresponding controls (Radwan et al., 2010). Additionally, the content of phenolics and flavonoids, as well as either soluble or insoluble proteins, also tend to increase following the occurrence of stress. Radwan et al. (2010) reported that BYMV-infected bean leaves had a protein content higher than the control, indicating the accumulation of pathogenesis-related proteins and concluded that changing antioxidant status and the accumulation of some antioxidant metabolites, as well as pronounced alterations in the protein composition, indicated a kind of plant response against pathogen invasion. Similarly, Hernandez et al. (2004) reported that a longterm effect of plum pox (PPV) virus infection produced an oxidative stress that was monitored as an increase of lipid peroxidation and protein oxidation and suggested an imbalance in antioxidative metabolism, which eventually resulted in the progress of PPV infection and related symptoms in peach plants.

In this study, an increase in TOS levels in infected pepper plants was evident when they were compared to corresponding control groups. In a similar manner, the total phenolic content, as well as free and conjugated phenols, were found to be higher under stress conditions. Therefore, OSI levels in infected pepper plants was found to be remarkably higher than those of the control group as a result of a decrease of TAS and an increase of TOS levels 
62

in infected pepper plants. The results clearly explain that oxidative stress is an important element in systemic virus infections where virus particles are distributed within the entire fruit (Dikilitas et al., 2011).

Vitamin C (ascorbate), which is one of the most powerful non-enzymatic antioxidants in plants, functions as a ubiquitous antioxidant in plants by scavenging a wide range of ROS via enzymatic and non-enzymatic reactions (Suza et al., 2010). Vitamin C is also a cofactor in at least eight enzymatic reactions, including several collagen synthesis reactions, which cause the most severe symptoms of scurvy when they are dysfunctional (www.food.gov. uk). Vitamin C provides the first line of defense against damaging ROS, and helps protect plant cells from many factors that induce oxidative stress including wounding, high salinity, and pathogen attack in living organisms. However, not certain is whether or not vitamin $C$ and antioxidant supplements, in general, prevent oxidative stressrelated diseases and promote health. In plants, ascorbic acid is associated with chloroplasts and apparently plays a role in ameliorating the oxidative stress of photosynthesis, and has a number of other roles in cell division and protein modification.

In this study, the vitamin $\mathrm{C}$ content of infected fruits was found to be significantly lower than those of control plants. The results outlined here regarding a decrease in vitamin $\mathrm{C}$ in pepper fruits with $\mathrm{PMMoV}$, and represents the first report. The correlation between the vitamin $\mathrm{C}$ content and the OSI of fruits was found to be negatively correlated. However, the negative correlation was more evident in infected fruits than within the corresponding control fruits. Clear is that an increase in OSI reduces the quality and quantity of fruits and crop yields. In general terms, the quality of fruits are measured in regards to their vitamins, as well as to their nutritional value as related to carbohydrates and the content of other organics. In the present case, a reduction in vitamin $\mathrm{C}$ resulted in a higher accumulation of oxidants in pepper fruits. As determined via calculations (OSI $=$ TOS $/$ TAS), stress indices were remarkably higher in infected fruits.

When phenolic compounds were examined, infected fruits displayed a higher content of phenolics as compared to controls. Phenolics are important metabolites in plant growth and in the defense against infection and injury. The presence of phenolic compounds in injured plants may have an important impact on oxidative stability and microbial safety (Karakaya et al., 2001). Although phenolic compounds do not have nutritious value, they are as important as other antioxidants (Holiman et al., 1996). In some cases, their accumulation has been considered as having health-promoting effects for consumers. In fact, phenolic accumulation may be regarded as a sign of the avoidance of abiotic and biotic stress factors. Although the accumulation of phenolic content may prevent the spread of disease agents in fruits or leaves, a higher accumulation of phenolics is not desired as a result of their interactions with proteins and carbohydrates (Robarbs et al., 1999). Since phenolic compounds result in discoloration in fruit or leaf tissues, an accumulation that exceeds a certain level could be toxic to consumers, as well as to infecting agents.

\section{Conclusions}

In this study, it has been found that both $\mathrm{CP}$ and FP increased after virus infection in pepper fruits. The change may result from a defense mechanism against infection by fruit. Although the phenolic content increased, an expected increase in other metabolites, such as antioxidant activity (TAS) in infected pepper plants, was not observed, which may be the result of the insufficient accumulation of antioxidant metabolites due to heavy infection.

In conclusion, fruits infected with $\mathrm{PMMoV}$ had lower TAS and TP levels and a lower vitamin $C$ content than those of corresponding control plants. Infected peppers accumulated a greater amount of TOS and, as a result, higher OSI. OSI levels are regarded as a good quality index for fruits as well as the status of plants.

\section{References}

Al-Saikhon MS, Howard LR Miller JC (1995). Antioxidant activity and total phenolics in different gentoypes of potato (Solanum tuberosum). J Food Sci 60:341-343.

Anandakumar P, Kamaraj S, Jagan S, Ramakrishnan G, Vinodhkumar R, Devaki D (2008). Capsaicin modulates pulmonary antioxidant defense system during benzo(a) pyrene-induced lung cancer in Swiss Albino mice. Phytoter Res 22:529-533.

Aycicek A, Erel O, Kocyigit A, Selek S, Demirkol MR (2006). Breast milk provides better antioxidant power than does formula. Nutrition 22:616-619.

Benzie IF, Strain JJ (1999). Ferric reducing/antioxidant power assay: direct measure of total antioxidant capacity of biological fluids and modified version for simultaneous measurement of total antioxidant power and ascorbic acid concentration. Met Enzymol 299:15-27.

Brunt AA, Crabtree K, Dallwoto MJ, Gibbs AJ, Watson L (1996). Virus of Plants. Wallingford, UK: Descriptions and lists from the VIDE Database, CAB International, 947-949 p.

Cao G, Srre E, Prior RL (1996). Antioxidant capacity of tea and common vegetables. J Agricult Food Chem 44:3425-3431.

Clark MF, Adams AN (1997). Characteristics of the microplate method of enzyme-linked immunosorbent assay for the detection of plant viruses plant viruses. J Gen Virology 34:475-83.

Dikilitas M, Kocyigit A, Yigit F (2009). A molecular-based fast method to determine the extent of DNA damages in higher plants and fungi. Afr J Biotechnol 8:3118-3127.

Dikilitas M, Guldur ME, Deryaoglu A, Erel O (2011). A novel 
method of measuring oxidative stress of pepper (Capsicum annuum var. 'Charlee') infected with tobacco mosaic virus. J Biosci 37:2425-2433.

Diwan H, Khan I, Ahmad A, Iqbal M (2010). Induction of phytochelatins and antioxidant defence system in Brassica juncea and Vigna radiata in response to chromium treatments. Plant Growth Regul 61:97-107.

Erel O (2004a). A novel automated direct measurement method for total antioxidant capacity using a new generation, more stable ABTS radical cation. Clinical Biochem 37:277-285.

Erel O (2004b). A novel automated method to measure total antioxidant response against potent free radical reactions. Clinical Biochem 37:112-119.

Erel O (2005). A new automated colorimetric method for measuring total oxidant status. Clinical Biochem 38:11031111.

Fodor J, Gullner G, Adam AL, Balaz B, Komives T, Kiraly Z (1997). Local and systemic responses of antioxidants to tobacco mosaic virus infection and to salicylic acid in tobacco. Plant Physiol 114:1443-1451.

Gazzani G, Papetti A, Massolini G, Daglia M (1998). Antioxdiative and prooxidant activity of water soluble components of some common diet vegetables and the effect of thermal treatment. J Food Chem 6:4118-4122.

Güldür ME, Çağlar BK (2006). Outbreaks of pepper mild mottled virus in greenhouses in Sanliurfa, Turkey. J Plant Pathol 88:339-342.

Hernandez JA, Rubio M, Olmos E, Ros Barcelo A, Martinez Gomez P (2004). Oxidative stress induced by long term plum pox virus infection in peach (Prunus persica). Physiol Plant 122:486-495.

Holiman PCH, Hertog MGL, Katan MB (1996). Analysis and health effects of flavonoids. Food Chem 57:43-46.

Imeh U, Khokhar S (2002). Distribution of conjugated and free phenols in fruits: Antioxidant activity and cultivar variations. J Agricult Food Chem 50:6301-6306.

Karakaya S, El SN, Tas AA (2001). Antioxidant activity of some foods containing phenolic compounds. Internat J Food Sci Nutrit 52:501-508.

Katoh H, Suzuki S, Saitoh T, Takayanagi T (2009). Cloning and characterization of VIGG, a novel virus-induced grapevine protein, correlated with fruit quality. Plant Physiol Biochem 47:291-299.

Keçeli MA (2008). Characterization of peppers for Antioxidant content and virus resistance. MSc. Thesis, The Graduate School of Engineering and Sciences of İzmir Institute of Technology, 1-89 p.

Kiraly L, Hafez YM, Fodor J, Kiraly Z (2008). Suppression of tobacco mosaic virus-induced hypersensitive-type necrotization in tobacco at high temperature is associated with down regulation of NADPH oxidase and superoxide and stimulation of dehydroascorbate reductase. J Gen Virol 89:799-808.
Kosecik M, Erel O, Sevinc E, Selek S, Demirkol MR (2005). Increased oxidative stress in children exposed to passive smoking. Internat J Cardiol 100:61-64.

Krishna AGG, Lokesh BR, Sugasini D, Kancheva VD (2010). Evaluation of the antiradical and antioxidant properties of extracts from Indian red chili and black pepper by in vitro models. Bulgar Chem Communic 42:62-69.

Navarro JM, Flores P, Garrido C, Martinez V (2006). Changes in the contents of antioxidant compounds in pepper fruits as different ripening stages, as affected by salinity. Food Chem 96:66-73.

Ozalp R (2009). VII Sebze Tarımı Sempozyumu, Atatürk Bahçe Kültürleri Merkez Araştırma Enstitüsü, 26-29 Agustos, Yalova-Turkey,250-255 p.

Panda SK, Khan MH (2009). Growth, oxidative damage and antioxidant responses in greengram (Vigna radiata L.) under short-term salinity stress and its recovery. J Agron Crop Sci 195:442-454.

Pengelly C, Wilson I, Hancock JT (2010). Nitric oxide scavenging by food: implications for in vivo effects of diet. British J Biomed Sci 67:15-19.

Perucka I, Materska M, Jachacz L (2010). Quality assessment of preparations made from dry fruits of Capsicum annuum L. Pepper. Zywnosc-Nauka Technologia Jakosc 17:30-39.

Radwan DE, Fayez KA, Younis Mahmoud S, Lu G (2010). Modifications of antioxidant activity and protein composition of bean leaf due to Bean yellow mosaic virus infection and salicylic acid treatments. Acta Physiol Plant 32:891-904

Robarbs K, Prenzler P, Tucker G, Swatsitang P, Glover W (1999). Phenolic compounds and their roles in oxidation processes in fruits. Food Chem 66:401-436.

Singleton VL, Orthofer R, Lamuela-Raventos RM (1999). Analysis of total phenols and other oxidative substrates by means of Folin Ciocalteau reagent. Met Enzymol 299:152178.

Suza WP, Avila CA, Carruthers K, Kulkarni S, Goggin FL, Lorence A (2010). Exploring the impact of wounding and jasmonates on ascorbate metabolism. Plant Physiol Biochem 48:337-350.

Velioglu YS, Mazza G, Gao L, Oomah BB (1998). Antioxidant activity and total phenolics in selected fruits, vegetables, and grain products. J Agricult Food Chem 46:4113-4117. 